\title{
Pendugaan Cadangan Karbon dengan Permodelan Penerapan Penanaman Asam Jawa pada Jalur Hijau Jalan-jalan Tol Semarang-Solo
}

\author{
Abdillah Rangga Fajar1* , Rifandi Raditya Ahmad1, \\ ${ }^{1}$ Program Studi Ilmu Lingkungan, Universitas IVET, Semarang \\ *Emal:rangga.fajar1989@gmail.com
}

\begin{abstract}
The increasing length of toll roads on the island of Java also increases the number of green lane that can be used for greening.One of the functions of the green road is for planting carbon-absorbing plants.Tamarind (Tamarindus indica) trees are a type of productive plants that have a carbon sink function.The purpose of this study is to estimate the carbon stock of a model of planting on the green lane of the Semarang-Solo toll road.This research was conducted in September 2019.The method used in this study is simulation calculation and allometric models.Calculation simulation method is used to determine the potential availability of land along the green lane of the Semarang-Solo toll road. Carbon reserve calculation method is done by nondestructive samplingby using an allometric model for the tamarind tree species. The application of this model can produce estimates of stored carbon stock approximately197.165 ton. Green lane has a very large utilization potential for carbon sequestration and should be used optimally.

Keywords: allometric model, carbon stock, green lane road, tamarind trees, Tamarindus indica.
\end{abstract}

\section{Pendahuluan}

Keberadaan Ruang Terbuka Hijau sebagai paru-paru kota sangatlah diperlukan oleh suatu kota atau daerah. Salah satu bentuk ruang terbuka hijau yang terdapat di suatu wilayah kota adalah hutan kota. Hutan kota dibagi dalam klasifikasi sebagai berikut ; jalur hijau, taman kota, kebun dan halaman, kebun raya, hutan raya dan kebun binatang, hutan lindung, kuburan dan taman pahlawan (Dahlan, 1992).

Jalur hijau jalan yang merupakan hutan kota tentunya memiliki peran yang sangat penting terhadap suatu kota. Tanaman atau pohon berumur panjang yang tumbuh di hutan maupun di kebun campuran merupakan tempat penimbunan atau penyimpanan karbon yang jauh lebih besar dari pada tanaman semusim. Oleh karena itu, hutan jenis pepohonan berumur panjang merupakan gudang penyimpan karbon tertinggi yang mampu mereduksi efek gas rumah kaca yang ada dialam bebas (Hairiah dan Rahayu, 2007).

Keunggulan tanaman asam jawa dibandingkan tanaman pinggir jalan lainnya seperti trembesi, bringin dan mahoni yaitu hampir semua bagian tanaman asam dapat digunakan untuk berbagai keperluan. Daun asam digunakan sebagai bumbu masakan, bahan obat, dan kosmetika. Bunga tanaman asammerupakan sumber madu yang penting bagi pengembangan budi daya lebah madu. Daging buah asam dimanfaatkan sebagai bumbu masakan dan obat tradisional. Buah asam banyak digunakan dalam industri minuman. Tepung biji asam sangat berperan dalam industri tekstil Indonesia, yaitu sebagai pengental cetak tekstil.

Penanaman pohon di perkotaan perlumemperhatikan karakteristik pohon. Karakteristik pohon yang tidak cocok sebagai tanaman pinggir jalan yaitu pohon yang mudah tumbang, menggugurkan banyak daun, sistem perakaran merusak jalan dan bagian bunga yang gugur dapat menyebabkan gatal, sehingga pohon asam jawa sangat baik sebagai tanaman pinggir jalan dilihat dari karakteristiknya dan keunggulan ekonomis lainnya (Dasuki, 1991).Selain itu tanaman asam jawa ini tidak memerlukan pengelolaan khusus sepanjang musim terutama penyiraman sehingga tidak memerlukan biaya pengelolaan. 


\section{Metode}

Penelitian ini dilakukan dengan membuat permodelanperhitungan ruas jalan tol Semarang-Solo, yang dilaksanakan pada bulan September 2019.

\section{Konsep Pengukuran Variabel}

Variabel yang akan diukur dalam penelitian ini adalah sebagai berikut.

a. Jumlah pohon asam jawa yang bisa ditanam di sepanjang jalur hijau jalan yang ada.

b. Total nilai biomassa dan cadangan karbon pohon asam jawa yang ada pada seluruh jalur hijau jalan yang direncankan.

\section{Metode Pengumpulan Data}

Panjang jalan yang dihitung dalam penelitian ini adalah seluruh panjang jalan milik Jasa Marga yaitu Ruas Tol Semarang - Solo. Data ini diperoleh melalui situs resmi PT. Jasa Marga yang menyebutkan panjang jalan tol sepanjang 72,64 km (Jasa Marga, 2019).

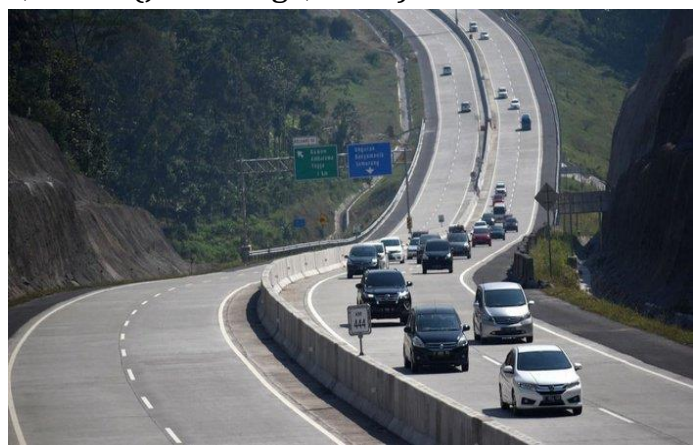

Gambar 1. Foto ruas jalan tol Semarang-Solo yang minim penghijauan

Perhitungan yang dilakukan pada penelitian ini merupakan simulasi terhadap suatu model penanaman, sehingga data diameter pohon merupakan rencana atau data yang diharapkan dalam permodelan untuk mendapatkan data yang seragam. Hal ini bertujuan untuk memudahkan proses perhitungan hasil simulasi.

Data biomassa pohon diperoleh dari parameter yang direncanakan yaitu diameter setinggi dada (1,3 $\mathrm{m}$ dari permukaan tanah) pada pohon. Biomassa yang dihitung hanya biomassa di atas permukaan tanah (Dasuki, 1991).

\section{Analisis Data}

Jumlah pohon asam jawa ini didapatkan dengan menghitung total panjang jalur hijau jalan yang ada kemudian dibagi dengan jarak tanam yang direncankan $(10 \mathrm{~m})$ dan dikalikan 2 sesuai dengan jumlah sisi penanaman pada jalan (sisi kanan dan kiri jalan). Dimana jarak tanam yang diterapkan dalam permodelan ini sebesar $10 \mathrm{~m}$ yang dideskripsikan pada gambar berikut.

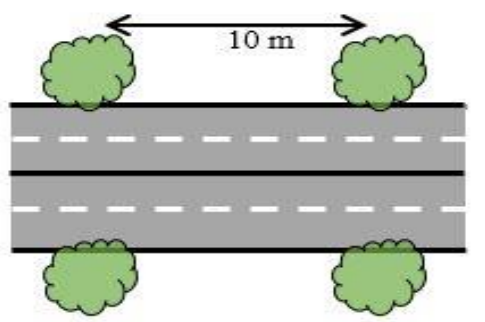

Gambar 2 . Model jarak penanaman asam jawa

Analisis biomassa dan cadangan karbon menggunakanpersamaan allometri pohon keraskarena asam jawa termasuk dalam kategori pohon keras. Allometri yang digunakan untuk mengukur pohon keras sebagai berikut (Santoso, 2005).

$$
\mathrm{B}=\mathrm{a} \mathrm{DBH}^{\mathrm{b}}
$$

\section{Dimana :}

$$
\begin{array}{ll}
\mathrm{B} & =\text { Biomass (ton) } \\
\mathrm{a} \text { dan } \mathrm{b} & =\text { konstanta } \\
\mathrm{DBH} & =\text { Diameter setinggi dada }
\end{array}
$$

Nilai Konstanta untuk pohon keras sebagi berikut :

$$
\mathrm{a}=0,133 \text { dan } \mathrm{b}=1,164 \text {. }
$$

Jumlah biomassa tersebut merupakan merupakan jumlah biomassa perpohon. Untuk mengetahui jumlah total biomassa maka harus dengan dikalikan dengan jumlah pohon yang ada.

Cadangan karbon diestimasi dengan mengalikan nilai biomassa pohon dengan nilai konversi sebesar 50\% bahwa secara kasar 50\% dari kandungan biomassa kayu tropis tersusun atas karbon (Brown, 1997).

$$
\text { Karbon }(C)=Y \times 0.5
$$

$$
\begin{aligned}
& \mathrm{C}=\text { Karbon }(\mathrm{kg}) \\
& \mathrm{Y}=\text { Biomassa }(\mathrm{kg})
\end{aligned}
$$




\section{Hasil dan Pembahasan}

\section{Keadaan Umum Wilayah}

Tol Semarang-Solo mulai dibangun pada 1 Maret 2009 oleh PT. Jasa Marga dengan total lintasan sepanjang 72,64 km. Jalan tol ini berada pada pegunungan sehingga memiliki kontur jalan yang naik dan turun serta memiliki jembatan ang panjang dan tinggi. Jalan tol ini merupakan bagian dari jalan tol Trans Jawa yang menghubungkan jalan tol Semarang dengan jalan tol Solo-Ngawi (Jasa Marga, 2019).

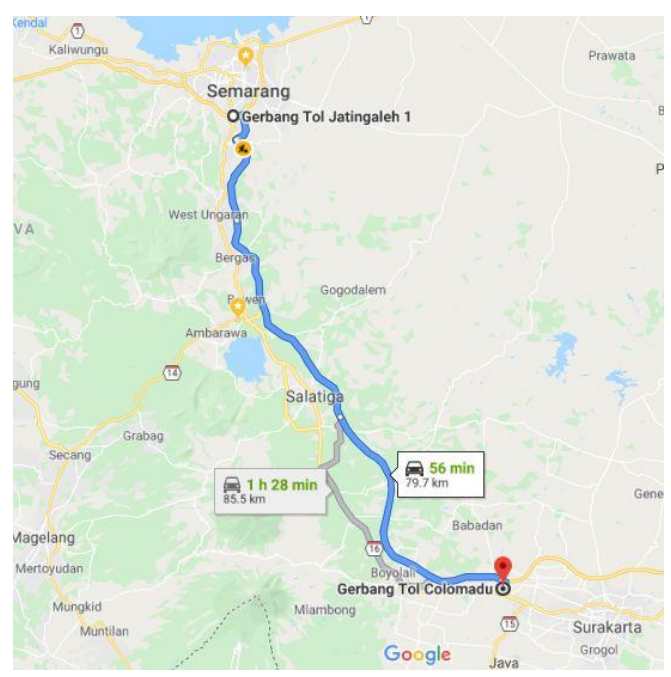

Gambar 2. Peta ruas Tol Semarang - Solo

\section{Gambaran Bentuk Permodelan}

Permodelan ini merupakan simulasi perhitungan potensi penanaman Asam jawa pada jalur hijau jalan yang ada di ruas Tol Semarang - Solo. Fokus penelitian ini hanya pada hasil simulasi perhitungan saja. Sehingga kondisi tanaman eksisting pada jalur hijau jalan ini tidak diperhiungkan. Upaya ini dilakukan untuk mempermudah mendapatkan hasil perhitungan dugaan cadangan karbon pada penerapan permodelan penanaman ini. Untuk itu diperlukan langkah-langkah dalam melakukan permodelan ini yaitu sebagi berikut.

a. Menentukan total panjang jalan milik PT. Jasa Marga yang berada di ruas Tol Semarang Solo. Langkah ini dilakukan dengan mencari data sekunder panjang jalan melalui situs resmi PT. Jasa Marga dan didapatkan data panjang jalan sepanjang $72,64 \mathrm{Km}$ atau $72.640 \mathrm{~m}$.

b. Menentukan jarak tanam pohon Asam jawa. Dalam permodelan ini ditentukan jarak tanam yang direncanakan adalah sejauh 10 m.

c. Menentukan diameter setinggi dada (DBH) pohon yang direncanakan yaitu sebesar 90 $\mathrm{cm}$ pada usia tanam 30 tahun (Rukmana 2005).

d. Menghitung total Biomassa dan cadangan karbon pada seluruh jalur hijau jalan.

\section{Analisis Jumlah Pohon}

Tabel 2. Hasil Perhitungan Jumlah Pohon

\begin{tabular}{|c|c|c|c|c|c|}
\hline No & Ruas Tol & $\begin{array}{c}\text { Panjang } \\
(\mathrm{m})\end{array}$ & $\begin{array}{c}\text { Jarak } \\
(\mathrm{m})\end{array}$ & sisi & $\begin{array}{l}\text { Jumlah } \\
\text { pohon }\end{array}$ \\
\hline 1 & $\begin{array}{l}\text { Tembalang } \\
\text { Ungaran }\end{array}$ & 16.302 & 10 & 2 & 3.260 \\
\hline 2 & $\begin{array}{l}\text { Ungaran- } \\
\text { Bawen }\end{array}$ & 11.314 & 10 & 2 & 2.263 \\
\hline 3 & $\begin{array}{l}\text { Bawen- } \\
\text { Salatiga }\end{array}$ & 17.611 & 10 & 2 & 3.522 \\
\hline 4 & $\begin{array}{l}\text { Salatiga- } \\
\text { Boyolali }\end{array}$ & 22.409 & 10 & 2 & 4.482 \\
\hline 5 & $\begin{array}{l}\text { Boyolali- } \\
\text { Kartosuro }\end{array}$ & 11.107 & 10 & 2 & 2.221 \\
\hline \multicolumn{2}{|c|}{ Total } & 72.640 & & & 15.748 \\
\hline
\end{tabular}

Jadi jumlah seluruh pohon asam jawa yang bisa ditanami pada jalur hijau jalan sepanjang $72.640 \mathrm{~m}$ di jalan tol Semarang-Solo sebanyak 15.748 pohon. Jumlah paling banyak berada di ruas tol Salatiga-Boyolali yaitu sebanyak 4.482 pohon, sedangkan jumlah yang paling sedikit berada di ruas tol BoyolaliKartosuro yaitu sebanyak 2.221 pohon. Hal ini membuktikan bahwa semakin panjang jalur hijau jalan akan semakin banyak pula jumlah pohon asam jawa yang bisa ditanam.

\section{Analisis Biomassa dan Cadangan Karbon}

Untuk menghitung nilai cadangan karbon maka perlu dicari terlebih dahulu jumlah serapan karbon atau biomassa pada lokasi tersebut, Dengan menggunakan persamaan allometri untuk jenis tanaman keras pada hutan tropis maka didapat nilai biomassa seperti terlihat pada tabel berikut.

Tabel 3. Hasil Perhitungan Nilai Biomassa/ pohon

\begin{tabular}{cccccc}
\hline No & $\begin{array}{c}\text { Nama } \\
\text { Pohon }\end{array}$ & $\begin{array}{c}\text { Konstant } \\
\text { (a) }\end{array}$ & $\begin{array}{c}\text { Konstant } \\
\text { (b) }\end{array}$ & $\begin{array}{c}\text { DBH } \\
\text { (cm) }\end{array}$ & $\begin{array}{c}\text { Biomass } \\
\text { (ton) }\end{array}$ \\
\hline 1 & $\begin{array}{c}\text { Asam } \\
\text { jawa }\end{array}$ & 0,133 & 1,164 & 90 & 25,04 \\
\hline
\end{tabular}

Sumber : Olah Data, 2019 
Setelah jumlah biomassa pada tiap pohon ditemukan kemudan kalikan dengan jumlah pohon yang bisa ditanam pada permodelan ini. Sedangkan untuk nilai cadangan karbon yang tersimpan sebesar $50 \%$ dari nilai biomassa yang ada (Brown, 1997).

Tabel 4. Hasil Perhitungan Cadangan Karbon

\begin{tabular}{ccccc}
\hline No & Ruas Tol & $\begin{array}{c}\text { Jumlah } \\
\text { pohon }\end{array}$ & $\begin{array}{c}\text { Biomassa } \\
\text { (ton) }\end{array}$ & $\begin{array}{c}\text { Cadangan } \\
\text { Karbon } \\
\text { (ton) }\end{array}$ \\
\hline 1 & $\begin{array}{l}\text { Tembalang } \\
\text { Ungaran }\end{array}$ & 3.260 & 81.360 & 40.815 \\
2 & $\begin{array}{l}\text { Ungaran } \\
\text { - Bawen }\end{array}$ & 2.263 & 56.665 & 28.333 \\
3 & $\begin{array}{l}\text { Bawen- } \\
\text { Salatiga }\end{array}$ & 3.522 & 88.190 & 44.095 \\
4 & $\begin{array}{l}\text { Salatiga- } \\
\text { Boyolali } \\
\text { Boyolali- }\end{array}$ & 4.482 & 112.229 & 56.115 \\
5 & $\begin{array}{l}\text { Kartosu- } \\
\text { ro }\end{array}$ & 2.221 & 55.613 & 27.807 \\
& & & $\mathbf{3 9 4 . 3 2 9}$ & $\mathbf{1 9 7 . 1 6 5}$ \\
\hline
\end{tabular}

Sumber : Olah Data, 2019

Berdasarkan table perhitungan tersebut total cadangan karbon pada jalur hijau jalan di jalan tol Semarang-Solo sebesar 197.165 ton karbon. Jumlah cadangan karbon terbesar berada pada ruan Tol Salatiga - Boyolali yaitu sebesar 56.115 ton. Sedangkan cadangan karbon yang paling sedikit berada di ruas tol BoyolaliKartosuro yaitu sebesar 27.807 ton.

\section{Simpulan}

Jumlah pohon Asam jawa yang bisa ditanam melalui hasil permodelan ini sebanyak 15.748 pohon dengan memanfaatkan jalan tol Semarang - Solosebagai jalur hijau jalan sepanjang 72,64 km.Nilai total cadangan karbon hasil penerapan permodelan penanaman asam jawa pada jalur hijau jalan di jalan tol SemarangSolo sebesar 197.165 ton. Hal ini menunjukan bahwa dengan adanya penerapan permodelan ini dapat menangkap karbon yang berlebihan di udara sesbesar 197.165 ton sehingga dapat mereduksi efek gas rumah kaca di alam bebas secara signifikan.

Melihat betapa tingginya potensi serapan karbon di udara dengan menggunakan permodelan penanaman ini, maka seharusnya permodelan seperti ini mulai diterapkan. Dengan penerapan permodelan ini diharapkan banyak membantu peningkatan ruang terbuka hijau bagi daerah lain sehingga membawa dampak yang positif bagi lingkungan dan makhluk hidup dalamnya.

\section{Daftar Pustaka}

Dahlan, N.E.1992. HutanKota untuk Pengelolaan dan Peningkatan Kualitas Lingkungan Hidup.Asosiasi Pengusahan Hutan Indonesia. Jakarta.

Hairiah, K., dan Rahayu, S. 2007. Pengukuran Karbon Tersimpan di Berbagai Macam Penggunaan Lahan. ICRAF. Bogor.

Dasuki UA. 1991. Sistematik Tumbuhan Tinggi. Pusat Antar Universitas Bidang Ilmu Hayati : ITB.

Santoso. 2005. Valuasi Ekonomi Ekosistem HutanMangrove di Kawasan Pondok Bali, DesaLegonwetan, Kecamatan Legonkulon,Kabupaten Subang, Jawa Barat. Bogor.Institut Pertanian Bogor.

N. S. Dudley and J. H. Fownes. 1992.Journal of Tropical Forest ScienceVol. 5, No. 1:68-73.

Rukmana, R. 2005. Budidaya Asam Jawa. Yogyakarta: Kanisius.

Brown, S. 1997. Estimasi Biomass and Biomass Change Of Tropical Forest. Roma: FAO forestry Paper.

[Jasa Marga]. 2019. Data Teknis dalam https://www.jasamarga.com/public/id/i nfoperusahaan/bisnis/anakperusahaan/d etail.aspx?title $=$ PT $\% 20$ Trans $\% 20$ Marga $\%$ 20Jateng\%20(TMI) 